\title{
ANALISIS DAERAH IRIGASI KATIMIN KABUPATEN SORONG
}

\author{
Tirsa Fajrin Mochtar ${ }^{1)}$, Muh Irfan Sigani ${ }^{2)}$,Hendrik Pristianto ${ }^{3)}$ \\ 1),2),3) Program Studi Teknik Sipil Universitas Muhammadiyah Sorong \\ Jalan Pendidikan No 27 Kota Sorong, Propinsi Papua Barat \\ Email :ctirsactirsa@gmail.com
}

\begin{abstract}
ABSTRAK
Kabupaten Sorong berbatasan dengan Kabupaten Raja Ampat di sebalah utara dan baratnya, sedangkan sebelah selatan berbatasan dengan Kabupaten Sorong Selatan dan sebelah timur berbatasan dengan Kabupaten Manokwari, terletak pada koordinat $00^{\circ} 33^{\prime}$ $42^{\prime \prime}-01^{\circ} 35^{\prime} 29^{\prime \prime}$ lintang selatan dan $130^{\circ} 40^{\prime} 49^{\prime \prime}$ - $132^{\circ} 13^{\prime} 48^{\prime \prime}$ bujur timur Luas wilayah Kabupaten Sorong mencapai $12.159,42 \mathrm{~km}^{2}$ yang terdiri dari daratan seluas $11.644,77 \mathrm{~km}^{2}$ dan lautan seluas $514,65 \mathrm{~km}^{2}$. . Pemerintah Indonesia melakukan usaha pembangunan di bidang pengairan yang bertujuan agar dapat langsung dirasakan oleh masyarakat dalam memenuhi kebutuhan air. Dalam memenuhi kebutuhan air khususnya untuk kebutuhan air di persawahan maka perlu didirikan sistem irigasi dan bangunan bendung. Kebutuhan air di persawahan ini kemudian disebut dengan kebutuhan air irigasi. Untuk irigasi, pengertiannya adalah usaha penyediaan, pengaturan dan pembuangan air irigasi untuk menunjang pertanian yang jenisnya meliputi irigasi permukaan, irigasi rawa, irigasi air bawah tanah, irigasi pompa, dan irigasi tambak. Tujuan irigasi adalah untuk memanfaatkan air irigasi yang tersedia secara benar yakni seefisien dan seefektif mungkin agar produktivitas pertanian dapat meningkat sesuai yang diharapkan. Kebutuhan air irigasi adalah jumlah volume air yang diperlukan untuk memenuhi kebutuhan evaporasi, kehilangan air, kebutuhan air untuk tanaman dengan memperhatikan jumlah air yang diberikan oleh alam melalui hujan dan kontribusi air tanah.
\end{abstract}

Kata Kunci : analisis daerah irigasi katimin, kabupaten sorong

\section{PENDAHULUAN}

Air adalah sumber daya alam yang sangat penting untuk kelangsungan hidup semua makhluk hidup. Air juga sangat diperlukan untuk kegiatan industri, perikanan, pertanian dan usaha-usaha lainnya. Dalam penggunaan air sering terjadi kurang hati-hatian sehingga perlu upaya untuk menjaga keseimbangan antara ketersediaan dan kebutuhan air melalui pengembangan, pelestarian, perbaikan dan perlindungan. Dalam pemanfaatan air khususnya dalam hal pertanian, dalam rangka memenuhi kebutuhan pangan serta pengembangan wilayah. Pemerintah Indonesia melakukan usaha pembangunan di bidang pengairan yang bertujuan agar dapat langsung dirasakan oleh masyarakat dalam memenuhi kebutuhan air. Dalam memenuhi kebutuhan air khususnya untuk kebutuhan air di persawahan maka perlu didirikan sistem irigasi dan bangunan bendung. Kebutuhan air di persawahan ini kemudian disebut dengan kebutuhan air irigasi. Untuk irigasi, pengertiannya adalah usaha penyediaan, pengaturan dan pembuangan air irigasi untuk menunjang pertanian yang jenisnya meliputi irigasi permukaan, irigasi rawa, irigasi air bawah tanah, irigasi pompa, dan irigasi tambak. Tujuan irigasi adalah untuk memanfaatkan air irigasi yang tersedia secara benar yakni seefisien dan seefektif mungkin agar produktivitas pertanian dapat meningkat sesuai yang diharapkan. 
Air irigasi di Indonesia umumnya bersumber dari sungai, waduk, air tanah dan sistem pasang surut. Salah satu usaha peningkatan produksi pangan khususnya padi adalah tersedianya air irigasi di sawah-sawah sesuai dengan kebutuhan. Kebutuhan air yang diperlukan pada areal irigasi besarnya bervariasi sesuai keadaan. Kebutuhan air irigasi adalah jumlah volume air yang diperlukan untuk memenuhi kebutuhan evaporasi, kehilangan air, kebutuhan air untuk tanaman dengan memperhatikan jumlah air yang diberikan oleh alam melalui hujan dan kontribusi air tanah.

tujuan penelitian ini adalah untuk menganalisis Daerah Irigasi Katimin. Diharapkan nantinya penelitian inidapat bermanfaat sebagai bahan masukan dan kajiandalam penentuan kebijakan serta untuk data dalamperancangan yang lebih lanjut pada instansiinstansiyang terkait.

\section{METODOLOGI}

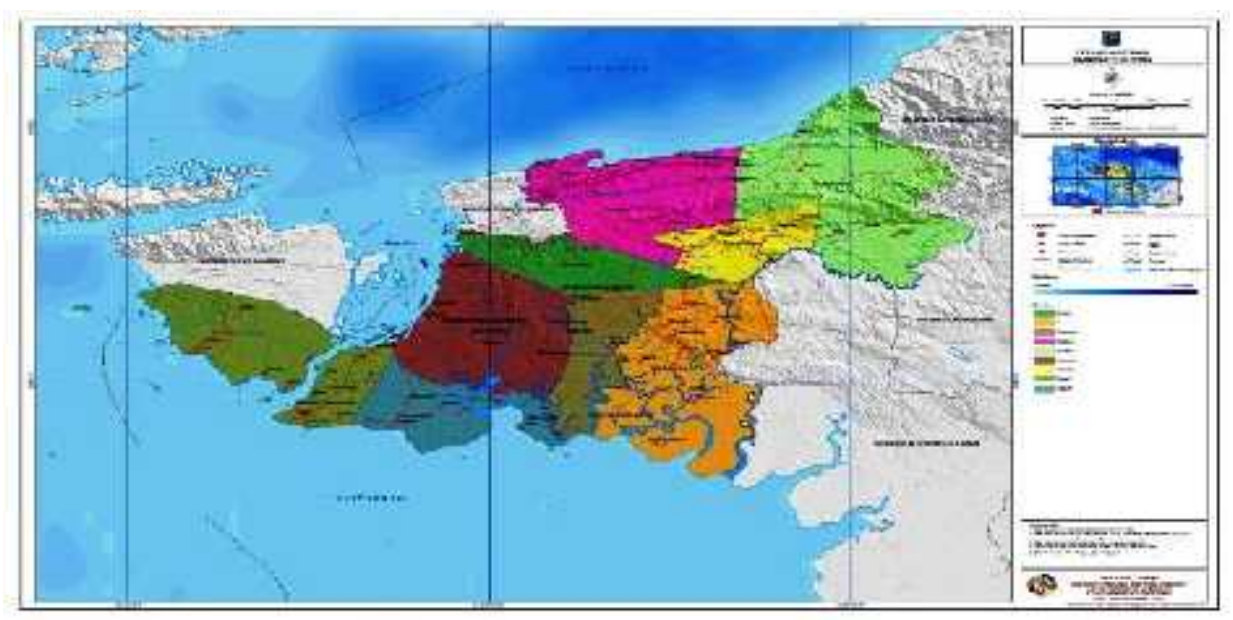

Gambar.Lokasi penelitian

Lokasi penelitian dilakukan di kampung Matawolot distrik Salawati, kabupaten Sorong.

Tahapan penyusunan artikel:

1. Menentukan tema

2. Pengambilan data di lokasi study

3. Analisa data

4. Membuat kesimpulan untuk menjawab tujuan penulisan artikel.

Semua metode penulisan dan analisa dalam artikel ilmiah ini merujuk pada panduan penulisan tugas akhir Fakultas Teknik Universitas Muhammadiyah Sorong tahun 2014 (Pristianto, Amri \& Rusdi, 2018 ). 
HASIL DAN PEMBAHASAN

Luas daerah irigasi persawahan yang berada di Katimin yaitu $175 \mathrm{Ha}$, yang terbagi beberapa lahan sawahseperti terlihat pada gambar di bawah ini.

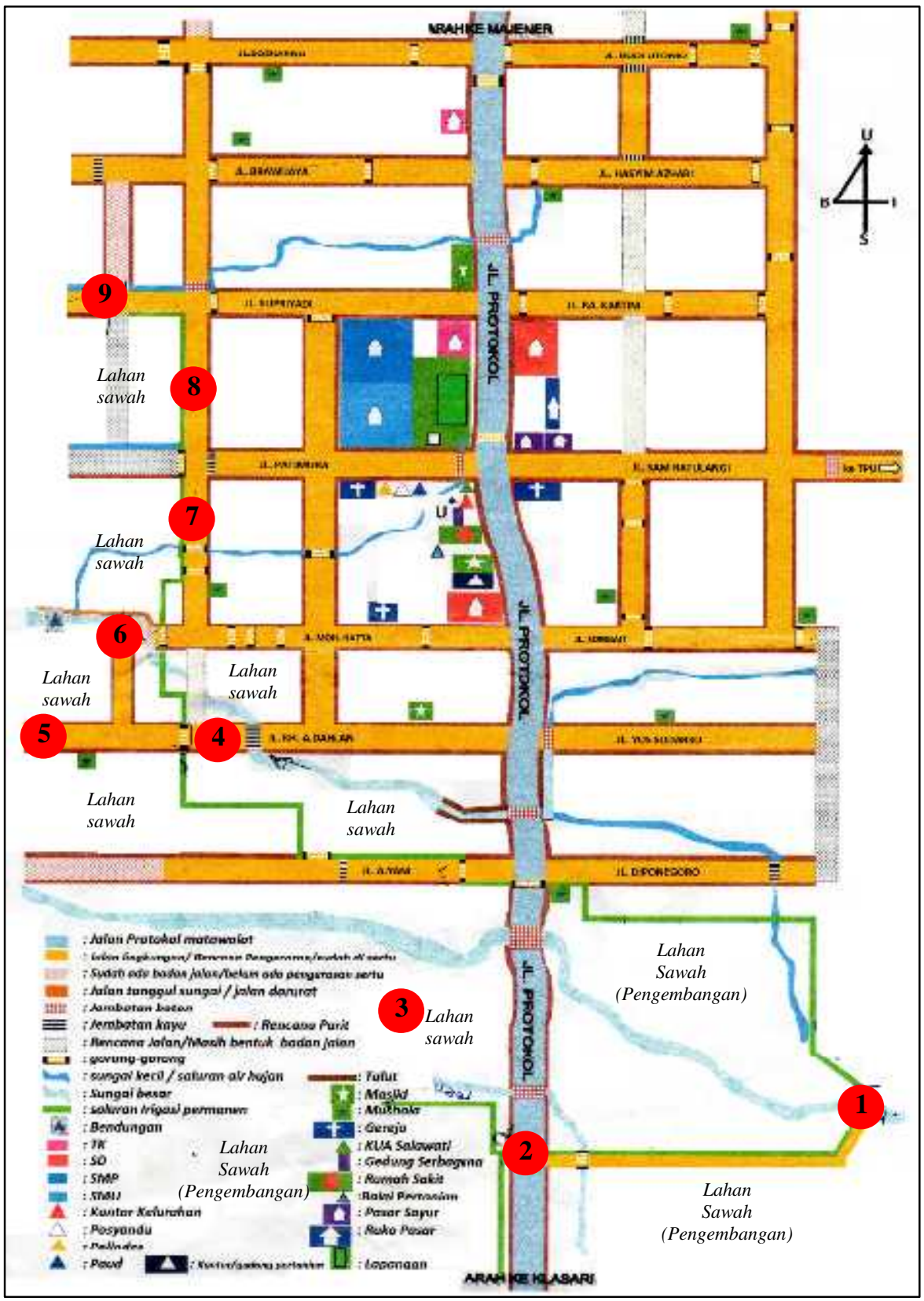

Gambar 2. Peta Lokasi Daerah Irigasi Persawahan 
Sumber air yang dimanfaatkan untuk mengairi area persawahan yang ada di daerah irigasi Katimin diambil dari sungai yang merupakan salah satu daerah irigasi dengan jaringan irigasisemi teknis. Maksud dari jaringan irigasi semi teknis yaitu memiliki bangunan sadap yang permanen/semi permanen. Bangunan sadap yangpada umumnya sudah dilengkapidengan bangunan pengambil dan pengukur. Jaringan saluran sudah terdapatbeberapa bangunan permanen (Intake), sistem pembagiannya belum sepenuhnyamampu mengatur dan mengukur. Karena belum mampu mengatur dan mengukurdengan baik, sistem pengorganisasian lebih rumit. Sistem pembagianairnya sama dengan jaringan sederhana, bahwa pengambilan dipakai untukmengairi daerah yang lebih luas daripada daerah layanan jaringan sederhana.

Sesuai dengan penelitian, daerah tersebut melakukan pola tata tanam Padi - Palawija Palawija. Tanaman palawija yang mereka tanam yaitu jagung, keladi, dll. Umumnya petani menerapkan pola tata tanam ini karena ketersediaan air dalam jumlah cukup. Pada saat kebutuhan air cukup petani di daerah irigasi katimin akan menanam padi, sebaliknya jika kebutuhan air kurang maka petani akan menanam tanaman palawija. Masa tanam padi dilakukan selama 3 bulan dalam satu tahun.

Hasil panen yang biasa diperoleh petani, yaitu:

- Padi

- Jagung

- Keladi

Kendala dan Hambatan

Dari penelitian yang dilakukan kelompok kami terdapat beberapa kendala dan hambatan, yaitu :

1. Kami menemukan ada beberapa kendala seperti sampah organik seperti batang kayu danjuga sedimen yang menumpuk di saluran irigasi;

2. Dari beberapa informasi yang kami peroleh, menurutpetugas penyuluh pertanian dan beberapa petani di kampung Matawolotdistrik Salawati pada saat musim kemarau, daerah irigasi persawahan mengalami krisis air, sebaliknya pada saat musim penghujan lokasi irigasi mengalami kelebihan volume air hal ini disebabkan oleh curah hujan yang tinggi, sehingga mengakibatkan persawahan di daerah tersebut tergenang air;

3. Kami juga memperoleh hambatan yaitu kurangnya informasi mengenai jumlah hasil panen yang dihasilkan oleh petani/tahunnya dan juga data curah hujan, dikarenakan kelurahan tidak mempunyai data tersebut;

4. Pada beberapa tempat, terdapat pintu air irigasi yang telah rusak. Hal ini tentu akan berdampak pada sistem irigasi yang tidak terkontrol.

\section{ANALISA}

1. Melakukan pembenahan terkait masalah sampah, yakni melakukan pembersihan sampah organik dan sedimen yang menumpuk di saluran irigasi secara periodik dan perlunya sosialisasi tentang peran masyarakat untuk selalu menjaga lingkungan dengan tidak membuang sampah sembarangan;

2. Kami menyarankan agar volume saluran irigasi dibesarkan hal ini tentu dapat mengurangi debit air yang berlebihan pada saat musim penghujan;

3. Sebaiknya pihak terkait memiliki data yang lengkap, seperti data hasil panen / tahunnya dan juga data curah hujan, sehingga analisis solusi dapat diketahui dengan pasti;

4. Perlunya pemeriksaan pintu air secara berkala, sehingga permasalahan dapat ditangani dengan cepat. 

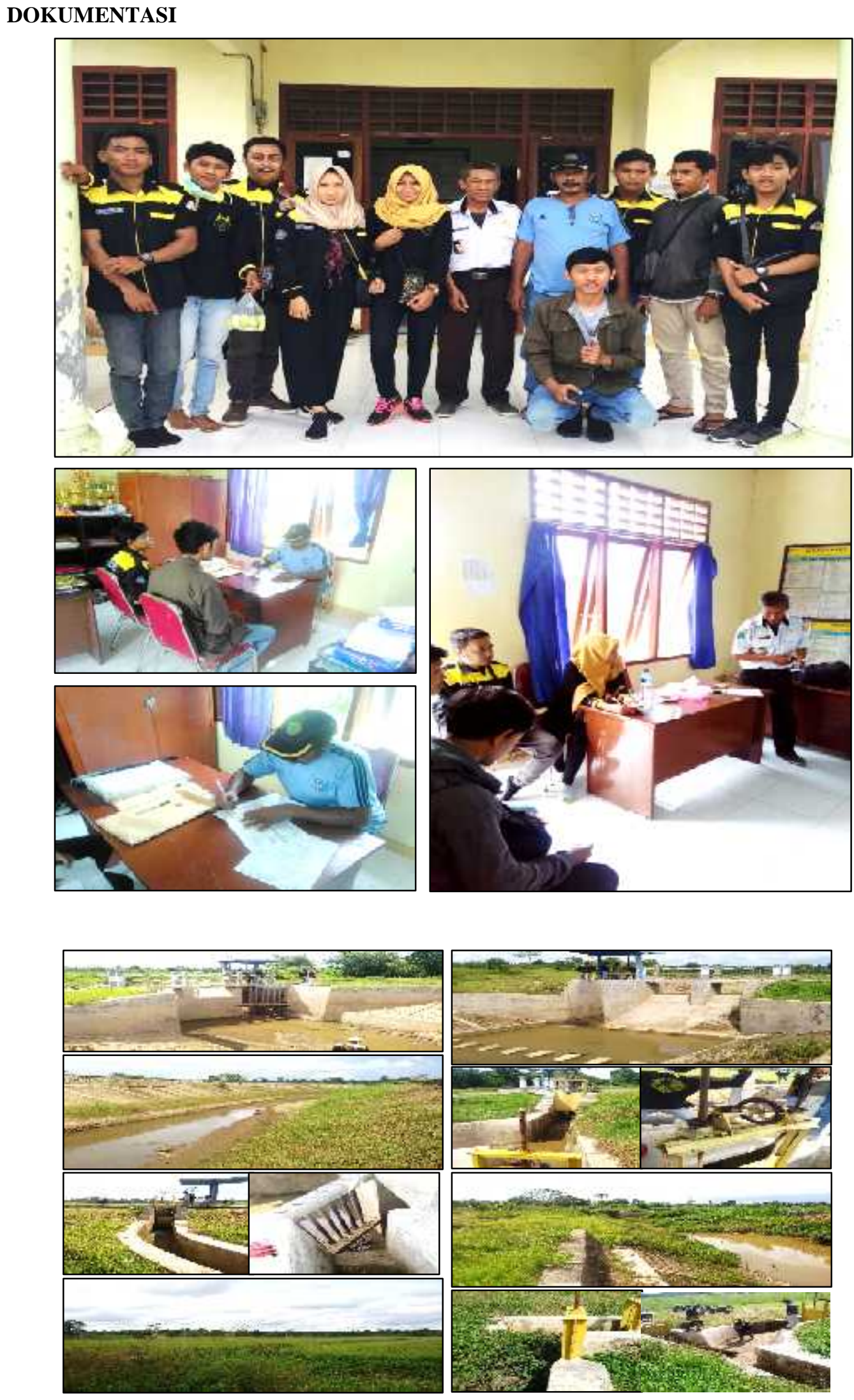


\section{KESIMPULAN}

1. Luas Daerah Irigasi yang terdapat di kampung Matawolot distrik Salawati kabupaten Sorong sebesar 175 Ha yang terdiri dari beberapa persawahan

2. Jaringan saluran sudah terdapatbeberapa bangunan permanen (Intake), sistem pembagiannya belum sepenuhnyamampu mengatur dan mengukur. Karena belum mampu mengatur dan mengukurdengan baik, sistem pengorganisasian lebih rumit.Pola tata tanam yang diterapkan yaitu, padi - palawija - palawija

3. Hasil panen yang dihasilkan berupa padi, jagung, keladi, dan lain sebagainya.

4. Pada saat kebutuhan air cukup petani di daerah irigasi katimin akan menanam padi, sebaliknya jika kebutuhan air kurang maka petani akan menanam tanaman palawija. Masa tanam padi dilakukan selama 3 bulan dalam satu tahun.

\section{REFERENSI}

1. Etd.reporsitory.ugm.ac.id

2. Kantor lurah daerah katimin

3. Peta-kota.blogspot.com

4. Data dari hasil survey / pengamatan yang dilakukan.

5. Pristianto, H., Amri, I., \& Rusdi, A. (2018). Pedoman Penulisan Tugas Akhir Fakultas Teknik Universitas Muhammadiyah Sorong. 